\title{
WALTER BENJAMIN LEITOR DE MARCEL PROUST UMA CRÍTICA BASEADA NO DECLÍNIO DA EXPERIÊNCIA
}

Natalie Araújo Lima é mestranda em Literatura, Cultura e Contemporaneidade pela PUC-RIO.

E-mail: natsal125@hotmail.com

\author{
Resumo \\ Este artigo quer associar as teorias \\ benjaminianas de crítica, linguagem, narrativa \\ e experiência à sua leitura de Em busca do \\ tempo perdido. Deseja-se mostrar que tais \\ temas encontram-se, sintetizados, no ensaio "A \\ imagem de Proust".
}

\begin{abstract}
This article links Benjamin's theories of critics, language, narrative and experience to his appointments of In Search of Lost Time. It intents to demonstrate that those themes are synthesized in Benjamin's essay "The image of Proust".
\end{abstract}

\section{A verdade está na forma}

O ensaio A imagem de Proust nos permite entrever o que era caro a Benjamin em termos literários - a importância dada à memória e à capacidade de contar, a perícia do sujeito moderno em narrar sua vivência - e os caminhos teóricos que cronologicamente antecederam e sucederam sua escrita (em especial, no primeiro caso, as teorias de crítica e linguagem, e, no segundo, as considerações sobre narrativa, história e experiência). Por isso, antes de abordar diretamente a crítica benjaminiana sobre Marcel Proust, gostaríamos de fazer algumas considerações sobre as ideias de Benjamin acerca de crítica de arte, narrativa e experiência.

A teoria da linguagem que Benjamin apresenta em 1916 com o ensaio Sobre a linguagem geral e sobre a linguagem humana ecoará em todos os seus trabalhos, e certamente, inclusive por sua proximidade cronológica, em sua tese de doutorado sobre a crítica de arte no romantismo alemão. Se a ideia de linguagem, para Benjamin, foi particularmente influenciada pela Cabala, foi também pelas místicas românticas e préromânticas, em especial pelo pensamento de Friedrich Schlegel e sua proposta de imanência linguística da obra de arte. Em $O$ conceito de crítica de arte no romantismo alemão, Benjamin desenvolverá a ideia de médium de reflexão a partir da imanência linguística, ideia essa já insinuada no ensaio de 1916, onde ele afirma que todos os elementos da Criação possuem uma linguagem própria ${ }^{i}$.

A ideia de imanência linguística, para os primeiros românticos alemães, está calcada em uma racionalidade imanente na natureza, ou seja, numa natureza que pensa a si mesma. Influenciados por Fichte e seu conceito de reflexão, os primeiros românticos vão admitir que tudo é reflexão de si (o que Benjamin chama de pensar do pensar), e que qualquer reflexão é a reflexão de uma forma. Isso significa dizer que é na imediatez das formas que se pode chegar ao espírito das coisas. Assim determina-se "a reflexão 
como reflexão de uma forma, demonstrando, desta maneira, a imediatez do conhecimento dado nela". (Benjamin, 2002, p. 29)

Além da imediatez do conhecimento pela forma, Benjamin trabalha a ideia dos primeiros românticos acerca do caráter infinito da reflexão. Também herdada de Fichte, mas um pouco transformada e até acentuada, a infinitude da reflexão não é vista pelo círculo de Iena como um continuum, mas como conexões que se sucedem. "A infinitude da reflexão é, para Schlegel e Novalis, antes de tudo não uma infinitude da continuidade, mas uma infinitude da conexão." (Benjamin, 2002, p. 34)

Se a natureza pensa a si mesma infinitamente por conexões, a obra de arte pensa a si mesma enquanto obra de arte e enquanto natureza, produzindo-se aí um pensar do pensar do pensar - a obra de arte reflete a poesia da própria natureza, inclusive do homem, desdobrando-se. Daí o valor que os primeiros românticos alemães atribuíram à arte, daí a conquista de uma autonomia da obra de arte em relação ao meio a partir desses filósofos.

A obra de arte é capaz de se pensar, de refletir sobre si mesma, e essa condição impõe-se à crítica, que precisará levar em conta, para a análise de uma obra, não os fatores externos, transcendentes, mas aquilo que é próprio à obra, sua linguagem. A obra de arte fala; é a ligação entre gênio e natureza, a diminuição radical da distância entre sujeito e objeto. Assim, para Benjamin, "a reflexão mesma é um médium - graças ao seu constante conectar; por outro lado, o médium em questão é tal que a reflexão move-se nele - pois essa, como o absoluto, movimenta-se em si mesma”. (Benjamin, 2002, p. 43)

O médium-de-reflexão, a partir dessa definição, estará presente em toda a tese, mas é no começo da segunda parte desta que Benjamin identifica dois estatutos-chave para que melhor entendamos a relação do médium-de-reflexão com a arte e com a crítica que ele reconhece: "A arte é uma determinação do médium-de-reflexão, provavelmente a mais fecunda que ele recebeu. A crítica de arte é o conhecimento do objeto neste médium-de-reflexão." (Benjamin, 2002, p. 69) Benjamin, consoante com os românticos, afirma também que a filosofia deve aprender com a arte: a forma não está desligada do conteúdo, a essência está ligada à aparência (e, assim, a verdade à beleza).

A teoria romântica da obra de arte é a teoria de sua forma [...] A forma é, então, a expressão objetiva da reflexão própria à obra, que forma sua essência. Ela é a possibilidade da reflexão na obra, ela serve, então, a priori, de fundamento dela mesma como um princípio de existência; através de sua forma a obra de arte é um centro vivo de reflexão0 (Benjamin, 1992. pp.80 e 81).

Além da imanência linguística da obra de arte, Benjamin compartilha com os primeiros românticos alemães da importância de tomar a tradição, o cânone, e relê-lo, inaugurando outro aspecto distintivo de uma nova postura crítica. Nesse sentido, vemos uma confluência na ideia de tradução - muito mais importante que traduzir o conteúdo 
de um texto é, traduzindo sua forma, manter sua poesia. Para Benjamin, tradução significa "resgatar em sua própria língua a língua pura, complementada na língua estrangeira, liberar, pela repoetização (Umdichtung), a língua pura, cativa na obra (Dichtung).” (Benjamin apud Furlan, 1996, pp. 553 e 554)

\subsection{Memória, vivência e experiência}

Como dissemos, o jovem Benjamin divide com os primeiros românticos alemães uma concepção comum do papel de crítico. Este não julga a obra com base em critérios transcendentes a ela, mas continua e traduz sua linguagem. Não há, na crítica (como não pode haver na tradução) sobrepujamento da linguagem filosófica sobre a artística, mas continuação, tornando arte o próprio filosofar sobre a arte - conduta que Benjamin em parte segue. "Crítica é, então, como que um experimentar na obra de arte, através do qual a reflexão desta é despertada e ela é levada à consciência e ao conhecimento de si mesma" (Benjamin, 2002, p. 74).

Alguns passos adiante, em sua tese de livre docência sobre o drama barroco alemão, de 1924, Benjamin complementa a definição romântica de crítica com a ideia de alegoria - uma possibilidade, pela escrita, de pensar o conceito de experiência a partir de uma crítica à modernidade. Com Trauerspiel, "Benjamin irá recortar a reflexão sobre a linguagem em um sentido mais amplo, em torno da escrita. Esta mudança irá determinar uma nova conceituação de experiência." (Muricy, 2009, p. 197) Seu objetivo é apresentar a teoria da alegoria como "uma forma de expressão, como a linguagem e como a escrita, e não como mera ilustração". (Muricy, 2009, p. 175) A nova conceituação, graças à prioridade dada à escrita, está calcada na ideia de construção da experiência, sendo a alegoria "uma escrita por imagens em que a fragmentação constitutiva atende tanto à exigência de um conhecimento imediato quanto à natureza do pensamento". (Muricy, 2009, p.20) Uma experiência construída, uma alternativa capaz de fazer face à derrocada geral da experiência tal qual Benjamin identifica, sobretudo em $O$ Narrador e Experiência e pobreza.

A derrocada geral da experiência, Benjamin a reconhece em nossa incapacidade de narrar, e aponta a ascensão do romance e o declínio do poema épico como prova de sua hipótese. Ao homem moderno teria sobrado não a experiência - que se compartilha coletivamente e que se transmite de geração a geração -, mas a vivência individual (Erlebnis), privada, estéril em sua capacidade poética e na transmissão de sabedoria.

A articulação de experiência e vivência constitui o par conceitual dessas análises da modernidade. A experiência (Erfahrung) é relacionada à memória individual e coletiva, ao inconsciente e à tradição. A vivência (Erlebnis) relaciona-se à existência privada, à solidão, à percepção consciente. Nas sociedades modernas, o declínio da experiência corresponde a uma intensificação da vivência. A experiência se torna definitivamente problemática e a sua possibilidade depende de uma construção vinculada à escrita. (Muricy, 2009. p. 198) 
Portanto, ao acreditar numa construção com base na escrita, Benjamin necessariamente será levado a analisar as formas narrativas de seu tempo. Sua conclusão é que, na modernidade, há lugar apenas para formas que priorizam mais o conteúdo que a forma (a informação). Dentro de uma escala de poeticidade, porém, o romance seria o único herdeiro da poesia épica - ideia que Benjamin compartilha com Georg Lukács - embora lhe seja impossível resgatá-la totalmente.

O que distingue o romance de todas as outras formas de prosa - contos de fada, lendas e mesmo novelas - é que ele nem procede da tradição oral nem a alimenta. Ele se distingue, especialmente, da narrativa. O narrador retira da experiência o que ele conta: sua própria experiência ou a relatada pelos outros. E incorpora as coisas narradas à experiência dos seus ouvintes. O romancista segrega-se. A origem do romance é o indivíduo isolado, que não pode mais falar exemplarmente sobre suas preocupações mais importantes e que não recebe conselhos nem sabe dá-los. (Benjamin, 2010, p. 201)

Enquanto o narrador, graças à tradição oral, conta com a memória coletiva para levar à frente sua narrativa e garante o caráter transmissível da experiência, ao romancista resta rememorar, "depois que a desagregação da poesia épica apagou a unidade de sua origem comum na reminiscência." (Muricy, 2009, p. 211) O romancista, rememorando e contando apenas com sua própria vivência, transmite a seu romance o caráter descontínuo dessa forma de escrita. Enquanto as narrativas geram sempre a pergunta “o que aconteceu depois?" (As mil e uma noites, a Torá e poemas épicos como A Odisseia são exemplos disso), o romance, "ao contrário, não pode dar um único passo além daquele limite em que, escrevendo na parte inferior da página a palavra fim, convida o leitor a refletir sobre o sentido de uma vida". (Muricy, 2009, p. 213)

Ainda estamos dentro da experiência na linguagem, mas agora diante da constatação de que a verdade nunca se totaliza, de que é apenas fragmentária, ou seja, de que o sentido não pode ser extraído a partir de uma imanência sempre acessível. É preciso destruir a obra, mortificá-la, para alcançar um sentido preso a uma tradição que não mais se sustenta; é preciso traduzir a obra a fim de que a alegoria se expresse, adotando uma postura bárbara de, reconhecendo a pobreza de nossa experiência, estar disposto a empreender algo novo.

O crítico bárbaro é o mesmo alegorista que, pela mortificação imposta à bela aparência, arrancava a obra de arte de uma falsa totalidade para mostrar a sua verdade fragmentada: a tarefa iconoclasta que destrói a tradição justifica-se na tarefa salvadora que descobre em suas ruínas a possibilidade de construção de uma nova experiência. (Muricy, 2009, pp. 207 e 208)

Bárbaro é quem Benjamin saúda no ensaio Experiência e pobreza, onde anuncia a ruptura radical com a tradição e o passado burgueses e exalta a destruição a partir de uma barbárie típica dos construtores, daqueles que abrem caminho sobre os escombros com honradez e dignidade para reconhecer 
[...] quando a experiência nos é subrtraída, hipócrita ou sorrateiramente. Sim, é preferível confessar que essa pobreza de experiência não é mais privada, mas de toda a humanidade. Surge assim uma nova barbárie. Barbárie? Sim. Respondemos afirmativamente para introduzir um conceito novo e positivo de barbárie. (Benjamin, 2010, p. 115)

Aqui barbárie significa tomar coragem para olhar de frente para a sociedade moderna, não negar seus horrores, e só assim ter a chance de transformá-los. Benjamin convoca o filósofo (e também o artista) para uma nova experiência - a de construção: experiência histórico-religiosa, misto de consciência de mortalidade e finitude com redenção quase metafísica. Falamos de um tempo que há de vir, suscitado por um momento redentor que abre uma fenda no passado, rompe com o curso da história e a reescreve graças às possibilidades oferecidas pela linguagem das coisas pequenas, quase insignificantes, guardadas pela memória. Falamos, em outras palavras, da possibilidade de rever o passado a fim de pensar o futuro. "O futuro, aqui, não é a projeção grandiosa do tempo na linha evolutiva da história, mas o seu desvio em direção ao passado, para que um ato de justiça possa libertá-lo." (Muricy, 2009, p. 14)

Com Erfahrung, Benjamin aborda a ideia de tradição fora da concepção que estabelece a história num continuum. Ela não precisa ser uma linha ininterrupta em que fatos se sucedem inevitavelmente, afirma o pensador alemão em suas teses sobre a história. Aqui, "o pensamento radical irrompe da mais profunda imersão da tradição" (Castro, 2007, s/p.). Onde se pode construir a experiência? Para Benjamin, a arte é o lugar da experiência salvadora, pois com ela é possível interromper o curso das dominações. Por ter uma linguagem própria, ou seja, ser um medium-de-reflexão da verdade que lhe é imanente, a arte, quando lida (mortificada) corretamente, é capaz de traduzir/expressar o mundo fora das abstrações conceituais, fora do discurso dominante.

É na poesia Baudelaire que Benjamin reconhecerá a construção de uma experiência construída dentro da modernidade. Pelo uso das alegorias em As flores do mal e da rememoração nas correspondances, Baudelaire teria conseguido associar, em sua poética, elementos atemporais e históricos, e com eles construído a experiência de modernidade. A tarefa da crítica benjaminiana, nesse caso, é encarar a si mesma como filosofia (ideia exposta no prefácio epistemológico do Trauerspiel) para interpretar a obra de arte de uma forma tal que possa evitar seu aprisionamento em uma continuidade linear, em conceitos exteriores a ela própria. Assim Benjamin procede "no caso de Baudelaire, da história da literatura, para lhe dar uma nova origem no presente da literatura. A crítica alegórica encontra o "poeta das alegorias"'. (Muricy, 2009, p.210)

Aqui o filósofo é aquele que, salvando a obra de arte pela crítica, tenta garantir a primeira a possibilidade de manter intacta sua verdade, o que significa desconfiar sempre do processo de transmissão das obras e de uma visão metafísica, estanque, das mesmas. Coloca-se aí, novamente, a problemática da tradição, que Benjamin soube tão bem analisar. Partindo de um ponto de vista moderno, a única possibilidade de tradição que nos resta está na sobrevida da obra e de seu teor de verdade, e isso pode ser 
garantido quando se admite que não existe, em qualquer obra, um valor eterno, mas um sentido, um teor de verdade que muda ao longo da história e da maneira com que o homem pratica a linguagem.

É dessa forma que o filósofo, o crítico, se insurge contra duas formas de totalidade: a pretensa totalidade da obra e a pretensa totalidade do processo de transmissão. "O que é durável é o estranho detalhe das referências alegóricas: um objeto do saber que se aninha em ruínas trabalhadas pelo pensamento. A crítica é mortificação das obras. Nisso, mais que em quaisquer outras produções, reside sua essência." (Benjamin apud Habermas, 1990, p.176)

Mortificando a obra, revirando-a, manuseando-a, nós, os modernos, podemos ter algum acesso à tradição, por uma lado, e à verdade de nossa época, por outro, sem nunca perder de vista a dimensão histórica (ou seja, sem nunca perder de vista a possibilidade de redimir o passado). Por mortificação da obra de arte entenda-se ruptura, destruição e reconstrução. É nessa ação que Benjamin espera uma abertura, e é na abertura que pode haver redenção, interrupção do curso do tempo e a invenção do futuro, deixando-se de andar por um tempo retilíneo, vazio e homogêneo. "O dom de despertar no passado as centelhas da esperança é privilégio exclusivo do historiador convencido de que também os mortos não estarão em segurança se o inimigo vencer." (Benjamin, 2010, pp.224 e 225)

Dessa forma, a tradição é arrancada ao mito e entregue à alegoria; é assim que se faz possível a aproximação do nome e o abandono - ainda que efêmero - da palavra vã. Como bem define Habermas, de um ponto de vista que remete tanto ao Benjamin místico quanto ao Benjamin materialista:

[...] a intenção de Benjamin orienta-se para um estado de coisas em que as experiências esotéricas de felicidade se tornem públicas e universais. Porque somente em um contexto comunicativo em que a natureza esteja incluída de uma forma fraterna e renovada, podem também os sujeitos erguer os seus olhos. (Habermas, 1990, p. 189)

\section{Benjamin leitor de Proust}

Parece-nos que Benjamin entende Em busca do tempo perdido como a experiência de Proust de tentar ter experiências expressas pela escrita e com base na rememoração. Além de tentar demonstrar essa afirmação, nosso objetivo é verificar se no ensaio A imagem de Proust e, como ponto de apoio, Sobre alguns temas em Baudelaire, podemos encontrar as concepções benjaminianas de crítica e linguagem, de um lado, e de experiência e narração, de outro.

Benjamin afirma que Proust empreendeu uma tarefa "elementar": "fazer a narração de sua própria infância.” (Benjamin, 1997, p. 107) Elementar porque, em tempos modernos, narrar já há muito se mostra uma forma de comunicação em seu ocaso, tendo dado espaço à informação. Ao narrar sua infância, ao tentar construir uma experiência de rememorar a infância, "os oito volumes de Proust nos dão ideia das 
medidas necessárias à restauração da figura do narrador para a atualidade”. (Benjamin, 1997, p. 107)

Se Marcel Proust eleva o escritor moderno à condição de narrador, ou melhor, à condição de alguém que busca o narrador em si, ele o faz graças à memória involuntária, capaz de levá-lo de volta à infância da Madeleine. Na célebre passagem, o narrador, um adulto, ao tomar chá com o bolinho, é remetido involuntariamente, ao sentir-lhe o sabor, à sua infância em Combray. Antes dessa memória, vinda diretamente de seu inconsciente, com que esforço relembra-se de Combray, dos pormenores da casa?! As lembranças alcançáveis em nível consciente apresentam-se sob a tutela do intelecto, fenômeno definido por Henri Bergson, em Matéria e memória, como memória pura (1999).

Proust desloca a ideia de memória pura desenvolvida pelo teórico francês juntamente com a ideia de duração - para a de memória involuntária, negando que "o recurso à presentificação intuitiva do fluxo da vida seja uma questão de livre escolha". (Benjamin, 1997, p.106) Nessa livre escolha Benjamin enxerga um forte afastamento da vivência moderna, que ele considera o contrário da experiência - ou, pior, uma degeneração dela. No centro da vivência está a percepção consciente dos acontecimentos, e esta, segundo sua interpretação de Além do princípio do prazer, de Freud, é tanto mais intensa quanto maior for o choque com que se recebem estímulos. Isso significa dizer que a apreensão dos estímulos chocantes (tão numerosos na era da técnica) se dá em nível consciente e que este tentará sempre proteger-se deles, evitando assim a experiência:

Quanto maior é a participação do fator do choque em cada uma das impressões, tanto mais constante dever ser a presença do consciente no interesse em proteger contra os estímulos; quanto maior for o êxito com que ele operar, tanto menos essas impressões serão incorporadas à experiência, e tanto mais corresponderão ao conceito de vivência. (Benjamin, 1997, p. 111)

Dessa forma, dependendo da memória involuntária para ter a experiência, Proust deixa por conta do acaso, nos diz Benjamin, se "cada indivíduo adquire ou não uma imagem de si mesmo, e se pode ou não se apossar de sua própria experiência." (Benjamin, 1997, p. 106) Aí está a principal diferença entre as experiências em Baudelaire e Proust, seu leitor: enquanto o primeiro alcança, com êxito, uma experiência coletiva, Proust acaba restringindo-se, ao contar com o acaso, a uma experiência pessoal. Esta, no entanto, não tem um caráter irremediavelmente privado, mas o adquire depois que as chances de uma integração com fatores externos se tornam nulas e depois que a própria experiência na modernidade se mostra inviável. Estamos, afinal, na era da linguagem jornalística, cujo propósito não é fazer com que o leitor incorpore à própria experiência as informações que lê, mas isolar os acontecimentos noticiados. Revela-se assim a crescente "atrofia da experiência." (Benjamin, 1997, p. 107) 
Proust é o autor de romances que - poderíamos chamar realmente de romances todos os volumes em que mistura gêneros de forma tão harmoniosa e tão pouco ortodoxa? -, isolado em sua doença, em sua riqueza, em sua condição de sujeito moderno, ao fazer uso da memória involuntária, torna-se um narrador que narra a experiência da busca da experiência pela memória. Seria a experiência da não experiência? Daquilo que não viveu? Grande leitor de Baudelaire ("ele foi um leitor incomparável de As flores do mal" (Benjamin, 1997, p. 131), Proust encontrou em sua poesia fortes afinidades com seu projeto literário, a ponto de Benjamin afirmar que "não existe nenhuma afinidade possível com Baudelaire que a experiência baudelairiana de Proust não abranja" (Benjamin, 1997, p.131)

A importância que Proust dá às correspondances deve-se ao fato de nelas reconhecer a cristalização de "um conceito de experiência que engloba elementos culturais" (Benjamin, 1997, p. 132), o que possibilitaria ao moderno Baudelaire dimensionar a derrocada da experiência tal qual se conhecia. Proust, afirma Benjamin em 1929 com A imagem de Proust, também trabalha com as correspondências; em seu caso, são as semelhanças que as determinam, e que por sua vez aparecem no universo de entrecruzamentos de reminiscências e envelhecimento, matéria-prima de que é feita a literatura proustiana. Embora tenham sido elevadas ao grau máximo com Baudelaire em sua poesia, "Proust foi o único a incorporar em sua existência vivida" (Benjamin, 2010, p.45) as correspondências por obra da memória involuntária e "sua força rejuvenescedora capaz de enfrentar o implacável envelhecimento". (Benjamin, 2010, p. 45) A autoabsorção dentro da obra que a vontade e a doença lhe impuseram são a prova disso.

Embora, com a memória involuntária, Proust nos permita vislumbrar a eternidade dos tempos entrecruzados simplesmente porque se recusa a desistir de lembrar-se do que pode vir a esquecer, sua vontade restauradora da experiência não se abre tanto para o coletivo quanto a de Baudelaire, capaz de falar da experiência das massas porque, uma vez reconhecendo a força da modernidade, curvou-se a ela e deixou-a falar. Nesse sentido, diz Proust sobre o poeta, suas "reminiscências são ainda mais numerosas; e note-se: não é o acaso [como acontece em Em busca do tempo perdido] que as evoca; por isso são decisivas, em minha opinião." (Proust apud Benjamin, 1994, p. 134)

A principal afinidade entre as obras de Proust e Baudelaire, para Benjamin, estaria principalmente no ato de rememorar, mas o que eleva Baudelaire a uma grandeza heróica é o reconhecimento, na forma da poesia, da precariedade da experiência de que fala Benjamin no ensaio Experiência e pobreza. A consciência da pobreza da experiência em Baudelaire estaria intimamente ligada à noção de sua dimensão histórica: graças ao spleen, à melancolia, não há mais aura.

\subsection{Uma crítica a partir da forma (e aonde se chega com ela)}


Escrito dez anos antes de Sobre alguns temas em Baudelaire, A imagem de Proust é um ensaio em que Benjamin se dedica a analisar os principais elementos da obra proustiana, como a memória e a experiência (de maneira diferente das considerações feitas no texto de 1939), mas também suas propriedades estéticas, incluindo aí as experimentações de linguagem feitas por Proust e o alcance alegórico (embora isso não seja mencionado diretamente) das imagens da memória. Também neste ensaio verificamos que o conceito de crítica de arte defendido por Benjamin em seus trabalhos anteriores é aqui posto em prática. É a partir da prática de crítica neste ensaio que chegaremos aos temas centrais de Proust para Benjamin.

Como vimos, Benjamin divide com os primeiros românticos alemães o conceito de crítica, embora os ultrapasse quando começa a trabalhar com a ideia de mortificação - uma maneira de, pela escrita enquanto experiência, arrancar um novo sentido da obra. Assim, o principal ponto em comum com os românticos não apenas permanece como se fortifica: o crítico não julga a obra, mas traduz sua linguagem. Dessa forma, procede o Benjamin tradutor/crítico de Proust. Não apenas traduziu-o de fato, mas escreveu sobre o que em sua obra havia de mais original e, depois, sob evidente influência, teceu suas memórias de criança em Infância em Berlim por volta de 1900.

No Benjamin leitor e tradutor de Proust não houve sobrepujamento da linguagem filosófica sobre a artística, mas continuação, tornando arte o próprio filosofar sobre a arte. Logo no início do ensaio, vemos a influência da teoria da linguagem benjaminiana dar seus primeiros sinais. Ao afirmar que Em busca do tempo perdido "conjuga a poesia, a memorialística e o comentário, até a sintaxe, com suas frases torrenciais (um Nilo de linguagem, que transborda nas planícies da verdade, para fertilizá-las)" (Benjamin, 2010, p. 36), Benjamin diz que, por todas as normas formais que excede, a obra de Proust constitui-se um caso excepcional na literatura de todos os tempos.

Benjamin justifica sua escolha pela análise de Em busca do tempo perdido em função do próprio autor, cuja condição de escrita tem como principal consequência uma grande discrepância entre vida e obra. Afinal, Proust não escreve sobre o que aconteceu, mas sobre o que se lembra que aconteceu. Nesse sentido, ele rememora a partir de sua memória involuntária, costurando, diz Benjamin, uma tessitura do esquecimento.

A comparação com Penélope, que tece reminiscências (no sentido literal que o termo assume em $O$ Narrador) para ganhar tempo, se mostra perspicaz. Pois "não seria esse trabalho de rememoração espontânea, em que a recordação é a trama e o esquecimento a urdidura, o oposto do trabalho de Penélope, mais que sua cópia?" (Benjamin, 2010, p. 37). Nesse autor que trocou o dia pela noite, que se recusava a dormir a fim de não esquecer e registrar todas as suas memórias - e isso está tanto no livro quanto nos hábitos de alcova - temos a imagem da luta contra o esquecimento, da vigília enquanto tentativa de eternizar as lembranças, de "não deixar escapar nenhum dos arabescos entrelaçados". (Benjamin, 2010, p. 37) A imagem de Proust que 
evocamos é a do homem excêntrico, rico e doente, deitado na cama de seu quarto, irremediavelmente determinado a tecer suas memórias enquanto havia tempo.

Quando menciona o depoimento de Gallimard sobre o enlouquecedor hábito de Proust de mexer, à exaustão, nas provas de revisão de seu livro, Benjamin puxa um fio de verdade e nos mostra que aí também se exercia a lei do esquecimento; para a qual a lembrança, e não o fato, é antídoto, e por isso mesmo antídoto sem limites, que não se restringe à esfera do vivido. Nesse sentido, engana-se quem deseja achar a unidade dos volumes de Em busca do tempo perdido unicamente no autor ou nas ações que lá ocorrem. Seu modo de textura está no ato da própria recordação. Ela é que dá a forma, ela é o ímã.

Benjamin faz a pergunta que todo leitor de Proust deve fazer a si mesmo: o que ele tão "freneticamente" buscava? Pelo que sua alma tanto ardia? Estava em busca de um tempo perdido na modernidade, e essa perda poderia ser atenuada senão aos pedaços, pela rememoração. $\mathrm{O}$ que se perde e o que se ganha? Se há um ensinamento nos volumes de Em busca do tempo perdido é o de que é preciso lembrar sempre, comentar sempre (duas ações tão judaicas!) a fim de extrair uma verdade possível - não total, mas verdadeira. Ao escrever todos os volumes de Em busca do tempo perdido, Proust sabia-se diante da impossível totalidade.

O que importa, como é o caso de Proust e sua Madeleine, não é o grande momento, mas aquele efêmero, banal e frágil, diz Benjamin. Se aí é que está o clarão de verdade, por mais fugaz que seja, aí também está o reencontro consigo mesmo, a empreitada mais que desafiadora imposta ao homem moderno. Essa condição leva Proust a construir frases cujas imagens revelam e saciam a nostalgia por aquilo que não existe mais. Com que talento de escritor ele expressa (sem representar) um mundo em seu ocaso!

Sem que use a palavra alegoria, Benjamin nos fala de um autor que, pela forma de sua escrita, expressa sua condição moderna em vez de representá-la. Afastando-se do mimetismo naturalista de Zola e Anatole France, Proust "fez do século XIX um século para memorialistas. O que era antes dele uma simples época, desprovida de tensões, converteu-se num campo de forças [...]".(Benjamin, 2010, p. 40) Com essa afirmação, Benjamin leva a literatura proustiana para o campo histórico (como veremos a seguir), o que à época deve ter sido uma ousadia, e ainda reprova o tipo de crítica que parecia ser feita na Alemanha de sua época: alheia ao interior da obra, muito mais preocupada com seus fatores externos do que com a possibilidade de deixá-la comunicar sua própria linguagem. Colocar a obra do esnobe, o frequentador de salões, à frente de nomes associados à denúncia das péssimas condições a que era submetida a população de Paris é duplamente desafiador: bate de frente com um pensamento de esquerda ortodoxo e um germanismo galopante.

É evidente que os problemas dos indivíduos que serviram de modelo a Proust provêm de uma sociedade saturada, mas não são os problemas do autor. Estes são subversivos. Se fosse preciso resumi-los numa fórmula, poderíamos dizer que seu foco é reconstruir 
toda a estrutura da alta sociedade sob a forma de uma fisiologia da tagarelice. (Benjamin, 2010, p. 41)

O interminável falar das tias de Marcel, das visitas e das pessoas que povoam aquele mundo de valores mumificados é composto pela tagarelice a que se refere Benjamin. Inevitável que se ria dela, de sua tentativa de manter-se de pé. Proust não se limita a fazer-lhe referência, mas lhe dá voz, e assim, pela forma, nos revela um jogo de forças calcado em valores moribundos que sustentam relações em uma classe social. A empreitada é bastante distinta, por exemplo (para continuar com o naturalismo), de outras encontradas no século XIX e no início do XX. Em vez de usar um universo esquemático a seu favor, Proust tece, pelo falatório dos personagens, seus valores, seu real. Assim vemos, estilhaçados, "a unidade da família e da personalidade, a ética social e a honra estamental. As pretensões da burguesia são despedaçadas pelo riso." (Benjamin, 2010, p. 41)

É nos salões que frequentou até pouco antes de começar a escrever Em busca do tempo perdido que Proust aprendeu a linguagem cifrada dos que dispõem de palavras para dizer tudo, mas escolhem-nas com o cuidado de quem toca bibelôs numa loja e pouco a pouco vai comprando centenas deles. Aqui, o mérito do observador Proust, nos diz Benjamin, não foi o de aprender como se comunicar adequadamente nas altas classes, mas de revelar em sua literatura que essas palavras fazem parte "de um jargão regulamentado por critérios de casta e de classe e não são acessíveis a estranhos". (Benjamin, 2010, p. 42)

Numa postura em que podemos antever as teses sobre história que conceberia pouco mais de dez anos depois, Benjamin nos mostra um Proust que espreita, pela linguagem, como um detetive, essa classe suspeita: "a camorra dos consumidores" (Benjamin, 2010, p. 44). Os que podem consumir muito aquilo a que poucos têm acesso como que exigem destes um retraimento pudico, uma subserviência silenciosa desenhada por gestos e códigos comuns ao mundo do consumo. Quando Benjamin afirma que "a análise proustiana do esnobismo, muito mais importante que sua apoteose da arte, é o ponto alto da sua crítica social" (Benjamin, 2010, p. 44), ele aponta para a máscara "feudal" de que a alta burguesia se investia, obrigada a dissimular seu poder de consumo pela linguagem e atada a valores aristocráticos em visível derrocada.

Nesse sentido, aos que acusam Proust de pôr-se a serviço de sua classe, Benjamin dá um aviso: não foi a serviço, foi à frente dela. Por isso a incompreensão da própria classe em relação à obra proustiana, por isso a não aceitação de parte da crítica. "O que ela [sua classe] vive começa a tornar-se compreensível graças a ele." (Benjamin, 2010, p. 45) A observação de Benjamin vai ao encontro de sua proposta de romper com o continuum da história graças à possibilidade de, pela memória involuntária, se chegar a um determinado momento passado a fim de modificá-lo.

A narração proustiana é interrompida pelos instantes de reminiscência, e o que se dá nesses instantes é justamente a superposição de passado e presente. Vê-se, então, uma 
maneira instigante de revisitar o tempo que passou, transformando também o posterior, como podemos acompanhar em sua narrativa. As fórmulas "antes eu não sabia" ou "depois eu compreenderia", utilizadas pelo herói proustiano com recorrência, evidenciam a maneira com que o romancista caminha entre passado, presente e futuro com naturalidade e, mais ainda, como ele apresenta a passagem de tempo e as mudanças sofridas, por ele próprio e pelas demais personagens, através dos saltos temporais sugeridos por essas expressões. Elas nada mais fazem do que explodir o continuum da história, como queria Benjamin. (Oliveira, 2009, p. 78) 
' Revela-se, indiretamente, uma leitura dos autores do círculo de Iena no ensaio de 1916.

\section{Referências bibliográficas}

BENJAMIN, Walter. "A imagem de Proust". In: . Magia e técnica, arte e política. Obras Escolhidas, vol. 1. São Paulo: Brasiliense, 2010.

Charles Baudelaire - Um lírico no auge do capitalismo. Obras Escolhidas, vol. 3. São Paulo: Brasiliense, 1997.

. "Experiência e pobreza". In: Magia e técnica, arte e política. Obras Escolhidas, vol. 1. São Paulo: Brasiliense, 2010.

O conceito de crítica de arte no romantismo alemão. São Paulo: Iluminuras, 2002.

. "O Narrador". In: . Magia e técnica, arte e política. Obras Escolhidas, vol. 1. São Paulo: Brasiliense, 2010.

"Sobre alguns temas em Baudelaire". In: Rua de mão única. Obras Escolhidas, vol. 2. São Paulo: Brasiliense, 1994.

"Sobre a linguagem em geral". In: . Sobre arte, técnica, linguagem e política. Lisboa: Relógio d’Água, 1992.

. "Sobre o conceito de história". In: Magia e técnica, arte e política. Obras Escolhidas, vol. 1. São Paulo: Brasiliense, 2010.

BERGSON, Henri. Matéria e memória. São Paulo: Martins Fontes, 1999.

CASTRO, Claudia. "Sobre o tapete da verdade: Benjamin e Hölderlin". Viso - Cadernos de estética aplicada, n. 2, maio-agosto 2007. Disponível em: <http://www.revistaviso.com.br $>$. Acessado em 18 de maio de 2010.

FURLAN, Mauri. "Linguagem e tradução em Walter Benjamin". In: Anais do XI Encontro Nacional da Anpol, João Pessoa, PB, 1996. Disponível em: < $\underline{\text { http://www.pget.ufsc.br/publicacoes/professores.php? }}$ $\underline{\mathrm{idpub}=46}>$ Acessado em 10 de dez. 2010.

HABERMAS, Jürgen. Habermas: Sociologia. São Paulo: Ática, 1990.

MURICY, Katia. Alegorias da dialética - imagem e pensamento em Walter Benjamin. Rio de Janeiro: Nau Editora, 2009.

OLIVEIRA, Marcela. Em busca do sentido perdido - Expressões literárias da queda da experiência moderna no pensamento de Walter Benjamin. Rio de Janeiro: PUC-Rio, 2009. 